\title{
Greening Ultrasound-Assisted Extraction for Sorghum Flour Multielemental Determination by Microwave-Induced Plasma Optical Emission Spectrometry
}

\author{
María Isabel Curti $\mathbb{D}^{1,2,3}$ Florencia Cora Jofre $\mathbb{C}^{1,},{ }^{1,2}$ Silvana $M$. Azcarate $\mathbb{D},{ }^{1,2}$ \\ José M. Camiña $\mathbb{D}^{1,2}$ Pablo D. Ribotta $\mathbb{D}^{3,4}$ and Marianela Savio $\mathbb{D}^{1,2}$ \\ ${ }^{1}$ Facultad de Ciencias Exactas y Naturales, Universidad Nacional de La Pampa, Av. Uruguay 151, Santa Rosa L6300XAI, \\ La Pampa, Argentina \\ ${ }^{2}$ Instituto de Ciencias de La Tierra y Ambientales de La Pampa (INCITAP), Mendoza 109, Santa Rosa L6302EPA, \\ La Pampa, Argentina \\ ${ }^{3}$ CONICET-UNC. Instituto de Ciencia y Tecnología de Alimentos Córdoba (ICYTAC), Córdoba, Argentina \\ ${ }^{4}$ Universidad Nacional de Córdoba, Facultad de Ciencias Exactas, Físicas y Naturales, Córdoba, Argentina
}

Correspondence should be addressed to José M. Camiña; jcaminia@gmail.com and Marianela Savio; marianelasavio@gmail.com

Received 7 July 2021; Accepted 10 November 2021; Published 6 December 2021

Academic Editor: Erwin Rosenberg

Copyright (c) 2021 María Isabel Curti et al. This is an open access article distributed under the Creative Commons Attribution License, which permits unrestricted use, distribution, and reproduction in any medium, provided the original work is properly cited.

\begin{abstract}
Sorghum is the fourth most important cereal produced in Argentina and the fifth worldwide. It has good agronomic characteristics and could be developed in arid areas, allowing a wide geographic distribution. Its starch content, higher than $70 \%$, makes it possible to obtain a good yield of flours. Nutritionally, it should be noted that the grain does not have the protein fraction called prolamins, which makes it suitable for consumption by people with celiac disease. The multielemental composition constitutes an important indicator of the nutritional profile of the grains and allows, together with other parameters, to select the most suitable varieties for human consumption. In its determination, the preanalytical stage is decisive to obtain a reliable result. Organic samples are a challenge for sample introduction systems that use plasma-based techniques. As an alternative to conventional pretreatment with a microwave-assisted digestion (MWAD), a greener, quick, and simple treatment is proposed, using ultrasound-assisted extraction (UAE) in diluted acid media. The UAE method accelerates analysis times, improves performance and productivity, and was applied to sorghum samples cultivated in the province of La Pampa (Argentina). Microwave-induced plasma optical emission spectrometry (MIP OES) was employed for the determination of $\mathrm{Cu}, \mathrm{K}, \mathrm{Mg}, \mathrm{Mn}, \mathrm{P}$, and $\mathrm{Zn}$. The detection limits found ranged from $0.6(\mathrm{Cu})$ to $89(\mathrm{P}) \mathrm{mg} \mathrm{kg}^{-1}$, and the precision expressed by the relative standard deviation (RSD) was $\leq 7.7 \%(\mathrm{Zn})$. For validation, a maize reference material (NCS ZC 73010) was evaluated. The principal component analysis revealed three different groupings related to the sorghum varieties' mineral profile.
\end{abstract}

\section{Introduction}

Sorghum (Sorghum bicolor L. Moench) is the fifth cereal produced worldwide [1]. Its relative plasticity at planting time permits the development in arid areas [2,3]. Sorghum grains are principally utilized for animal feeding and exportation in agricultural countries. However, it is an important source of nutrients especially for inhabitants of Asia and Africa who consume it in simple preparation [3]. In this regard, sorghum plays an important role in the nutrition of the most food-insecure regions of the world.

In the last few years, sorghum grain has increased recognition for its health-promoting benefits. The pericarp is rich in phenolic compounds, micronutrients, and dietary fiber, while in the endosperm starch is the main component $[4,5]$. From a mineral nutrition point of view, the grains contain minerals such as phosphorus, magnesium, and potassium in varying amounts depending on the hybrids and 
are also an important source of iron and zinc, comparable to rice and wheat [6]. Additionally, a highlight attribute is the lack of gluten, which makes it suitable for consumption by people with celiac disease $[7,8]$.

The mineral content of sorghum flours is nutritionally relevant as an affordable source of nutrients. Sorghum is utilized in a wide range of food products such as beverages, porridges, and flatbreads [9]. The use of sorghum flour is also appreciated for being a gluten-free raw material available for baked products production. Numerous studies endorse the use of sorghum in the elaboration of bread, cakes, and cookies with good technological and sensory properties [10-14].

Green and equitable analytical chemistry focus on environmentally friendly analytical procedures application, highlighting their availability to society [15]. Thus, much emphasis should be placed on making determinations with easily available instruments and nonpolluting procedures. Microwave-induced plasma optical emission spectrometry (MIP OES) stands out as a low-cost acquired, sensitive, robust, and selective technique; its versatility allows a complete mineral profile quantification [16-18].

For plasma-based techniques, such as MIP OES, a total sample matrix decomposition is needed to solubilize the analyte, but this is an analytical process stage in which many mistakes can be made [19]. The application of analytical sample preparation techniques is hampered by the significant cost of instruments, leading to the use of low-cost extraction units, known for domestic and everyday use. Several works determined sorghum mineral composition, reducing the organic matter to ashes and then restituting it in acid before analysis [20, 21]. However, microwaveassisted digestion (MWAD) is considered the state of the art in sample preparation as it reduces solvent consumption and is faster than acid digestion, combining high temperature and high pressure [22]. Notwithstanding, due to its low cost and for the unique conditions provided by acoustic cavitation, ultrasound-assisted extraction (UAE) has evolved in the last decades as an efficient alternative to MWAD, enhancing solid sample pretreatment, promoting green aspects such as energy requirements, and minimizing solvent consumption [23-26].

Hence, a simpler and greener sample preparation method for sorghum flours based on UAE is proposed, improving performance and productivity. In order to assess nutritional profile, the multielemental determination of different sorghum cultivars from La Pampa, Argentina, was performed by MIP OES. Moreover, principal component analysis (PCA) was performed to find similarities and differences among sorghum hybrids.

\section{Experimental}

2.1. Samples. Sorghum flours were obtained from commercial hybrids of brown sorghum grains provided by Instituto Nacional de Tecnología Agropecuaria (Estación Experimental Anguil, La Pampa, Argentina): TOB $41 \mathrm{~T}$, TOB EXP 903, ACA 548, ACA XP GR 209, ACA GR 233, ARGENSOR 110 T, GEN 11T, GEN 311 T, SUMMER II,
SPRING T 60, EXP 483, TAMAR 2 GR, HS 26 LT, PS (graniferous sorghums); ARGENSOR 151 DP, GEN 417 SLT 55 (dual-purpose sorghums); and GS1, GS2, GSD 3, GSD 4 (forage sorghums).

Sorghum hybrids used in this study were carefully cleaned and freed from foreign materials. Cleaned sorghum samples (approximately 500 g) were conditioned at 12\% humidity before milling. After that, the grains were subjected to a high-speed action mill (FOSS Cyclotec ${ }^{\mathrm{TM}} 1093$, Spain) with a $0.5 \mathrm{~mm}$ screen to produce the flour.

The sorghum flour samples were then packaged in a polyethylene bag and kept refrigerated $\left(4-5^{\circ} \mathrm{C}\right)$. The samples were dried in an oven at $60^{\circ} \mathrm{C}$ for $2 \mathrm{~h}$ until analysis.

2.2. Instrumentation. Multielemental determination was executed by MIP OES Agilent MP 4100 (Santa Clara, USA) which encompasses an inert OneNeb nebulizer, a doublepass glass cyclonic spray chamber, and an SPS3 autosampler system. MIP OES owns a Czerny-Turner monochromator with a VistaChip charge-coupled device (CCD) array detector. MIP OES 4100 runs with an online $\mathrm{N}_{2}$ generator. For each analyte studied, the operating parameters and instrumental conditions such as nebulizer gas pressure (NGP) and viewing position (VP) were automatically optimized by the MP Expert software (Agilent Technologies), and they are shown in Table 1. An Anton Paar MW 3000 microwave system (Graz, Austria) and an Ultrasound (Testlab) with a power of $160 \mathrm{~W}$ and frequency of $40 \mathrm{kHz}$ were used for sample preparation $(25$ samples at time).

2.3. Reagents and Solutions. Ultrapure deionized water (resistivity of $18.2 \mathrm{~m} \Omega$ ) was produced by a Millipore ultrapurifier (Darmstadt, Germany). All reagents were of analytical grade and all solutions were ready using distilleddeionized water. A Berghof ${ }^{\circledR}$ subboiling distiller system (Eningen, Germany) was used to obtain concentrated $\mathrm{HNO}_{3}$ (Merck, Darmstadt, Germany). Hydrogen peroxide (30\% (w/w), Sigma-Aldrich) was also employed.

For MIP OES analytical calibration, standard solutions for $\mathrm{Cu}, \mathrm{K}, \mathrm{Mg}, \mathrm{Mn}, \mathrm{P}$, and $\mathrm{Zn}$ were prepared in a matrix of $0.14 \mathrm{~mol} \mathrm{~L}^{-1} \mathrm{HNO}_{3}$, with a multielemental standard SCIENCE Plasma CAL.

All material used throughout the study was cleaned with $10 \% \mathrm{HNO}_{3}$ for $24 \mathrm{~h}$ and rinsed several times with ultrapure water.

2.4. Ultrasound-Assisted Extraction. The UAE was carried out by accurately weighing masses around $0.5000 \mathrm{~g}$ of dry samples, and they were transferred to polypropylene metalfree flasks with a screw cap. A volume of $5.00 \mathrm{~mL} \mathrm{HNO}_{3}$, $7 \mathrm{~mol} \mathrm{~L}^{-1}$, and $1.00 \mathrm{~mL}$ of $\mathrm{H}_{2} \mathrm{O}_{2}$ was added; then they were placed into a thermostated water bath at $100{ }^{\circ} \mathrm{C}$ for $30 \mathrm{~min}$; after that, UAE was performed for $30 \mathrm{~min}$. The obtained suspensions were diluted up to $30.00 \mathrm{~mL}$. Digestions were made in triplicate. Also, blank reagents were run. 
TABLE 1: Instrumental parameters and analytical figures of merits of the proposed UAE method by MIP OES.

\begin{tabular}{|c|c|c|c|c|c|c|}
\hline \multirow{2}{*}{$\begin{array}{l}\text { Instrumental parameters } \\
\text { Plasma power }(\mathrm{W})\end{array}$} & \multicolumn{6}{|c|}{ Operational conditions } \\
\hline & \multicolumn{6}{|c|}{1000} \\
\hline Stabilization time (s) & \multicolumn{6}{|c|}{10} \\
\hline Background correction & \multicolumn{6}{|c|}{ Auto } \\
\hline Integration time $(\mathrm{s})$ & \multicolumn{6}{|c|}{3} \\
\hline Nebulizer & \multicolumn{6}{|c|}{ OneNeb ${ }^{\circledR}$} \\
\hline Spray chamber & \multicolumn{6}{|c|}{ Double pass cyclonic } \\
\hline Sample floe rate (rpm) & \multicolumn{6}{|c|}{15} \\
\hline Replicates & \multicolumn{6}{|c|}{3} \\
\hline Analyte & $\mathrm{Cu}$ & $\mathrm{K}$ & $\mathrm{Mg}$ & $\mathrm{Mn}$ & $\mathrm{P}$ & $\mathrm{Zn}$ \\
\hline Wavelength (nm) & 324.754 & 766.491 & 285.213 & 403.076 & 213.618 & 213.857 \\
\hline Viewing position & 0 & -10 & -10 & 0 & -10 & -10 \\
\hline Nebulizer gas pressure $(\mathrm{kPa})$ & 180 & 220 & 200 & 240 & 220 & 160 \\
\hline $\operatorname{LOD}\left(\mathrm{mg} \mathrm{kg}^{-1}\right)$ & 0.6 & 3.1 & 11.5 & 2.0 & 52 & 2.0 \\
\hline LOQ ( $\left.\mathrm{mg} \mathrm{kg}^{-1}\right)$ & 1.9 & 9.5 & 34.9 & 6.0 & 172 & 6.0 \\
\hline $\operatorname{RSD}(\%)$ & 5.43 & 4.80 & 0.27 & 7.11 & 7.72 & 1.48 \\
\hline$R^{2}$ & 0.99 & 0.99 & 0.99 & 0.99 & 0.99 & 0.99 \\
\hline
\end{tabular}

2.5. Microwave-Assisted Digestion. For comparative purposes, the MWAD was performed by accurately weighing masses around $0.5000 \mathrm{~g}$ of dry samples; they were transferred to the hermetically sealed $100 \mathrm{~mL}$ PTFE tubes. A volume of $5.00 \mathrm{~mL} \mathrm{HNO}_{3}, 7 \mathrm{~mol} \mathrm{~L}^{-1}$, and $1.00 \mathrm{~mL}$ of $\mathrm{H}_{2} \mathrm{O}_{2}$ was added. The tubes were located in the Anton Paar microwave system and the next microwave-assisted heating program was implemented: 1 st step-15 min for ramp time up to $190^{\circ} \mathrm{C}$ and up to $1200 \mathrm{~W}$; 2nd step-15 min for hold time at $190{ }^{\circ} \mathrm{C}$, up to $1200 \mathrm{~W}$. Afterward, samples were relocated in a volumetric tube and diluted up to $30.00 \mathrm{~mL}$. Digestions were made in triplicate. Blank reagents were run.

2.6. Accuracy Evaluation. For method accuracy evaluation, experiments were performed using a certified reference material (CRM): Maize Flour (NCS ZC 73010 Mealie) from National Analysis Center For Iron and Steel (NCS) Testing Technology Co., Ltd. Reference materials were prepared using the same conditions proposed for the sorghum flour samples.

\subsection{Data Analysis}

2.7.1. Calibration and Validation Sets. Calibration models for each element were performed using five concentration levels in triplicate, and a blank solution was always considered. All experiments were carried out three times, and data were expressed as mean range values.

The proposed method was validated in terms of the following performance parameters: linearity, limits of detection and quantification, and repeatability, achieved under the optimal working conditions. Limits of detection (LOD) and quantification (LOQ) were calculated based on the International Union of Pure and Applied Chemistry (IUPAC) recommendations. Repeatability and recoveries (95\% confidence level) were calculated based on analyzed certified reference materials.
2.7.2. Principal Component Analysis (PCA). In order to understand the correlations between the calculated multiple mineral concentration and to consistently evaluate the sorghum genotypes, a PCA was conducted. PCA is useful to elucidate the complex nature of multivariate relationships and to understand the structure of multivariate complex datasets revealing hidden patterns [27]. Thus, PCA provides an overview of the main information contained in two-way data, which can be visualized in a space of two or three dimensions.

First, PCA models as exploratory tools to ascertain the most appropriate data pretreatment procedure and to find outliers and main patterns. Similarities and differences between samples were studied by observing the scores of the principal components, and the importance of variables was studied by the loadings plots. Accordingly, PCA was performed on a dataset arranged in a matrix $(40 \times 6)$.

2.7.3. Software. Using MATLAB (2014b) (The Mathworks, Natick, MA, USA), calculations associated with calibrations, merit figures, recovery studies, and statistical tests, in addition to preprocessing data, correlation coefficients, and PCA, were performed. Environment-based routines (available in https://www.iquironicet.gov.ar/descargas/univar.rar) along with other home-based routines were employed [28]. Fisher's variance comparison was applied to evaluate the data homogeneity and heterogeneity. Calibrations were performed by adjusting the lines with the least-squares criterion and the linear interval was evaluated through an $F$ test. Significant differences between treatments were carried out through average comparison by $t$-test. All tests were evaluated at $95 \%$ confidence level.

\section{Results and Discussion}

3.1. Instrumental Optimization. In plasma-based atomic emission spectrometry techniques, such as MIP OES, efficient transport of particles through the sample introduction system and identical decomposition, as well as atomization/ 
excitation processes of standards and samples, is desirable $[29,30]$. Through the NGP, the sample solution turns into a finely divided droplet forming a fine mist, being transported into the atomization region. To enhance matrix handling, in MIP OES, the plasma torch is vertically oriented into the cavity, to avoid distortions in the plasma and unfavorable phenomena occurring with the sample transport; nevertheless, it has axial viewing for the finest detection limits and optimal sensitivity. In this instrumental arrangement, emission signals from the plasma are directed into the preoptic system, which works in conjunction with a fastscanning monochromator (Czerny-Turner monochromator-600 $\mathrm{mm}$ focal length) and a charge-coupled device (CCD) detector [29].

Some of MIP OES' main limitations include some fixed parameters, such as a microwave-applied power fixed at $1000 \mathrm{~W}$ [29]. However, the equipment software carried out a scan of NGP and viewing position (VP), selecting the one with the highest intensity. Thus, to attain the best analytical performance, for each analyte wavelength, the VP was automatically optimized by the MIP OES. Also, the NGP was optimized to acquire the highest analytical signal for each element. For its relevant importance from a nutritional point of view, $\mathrm{Cu}, \mathrm{K}, \mathrm{Mg}, \mathrm{Mn}, \mathrm{P}$, and $\mathrm{Zn}$ were selected as the majority minerals present in sorghum grains. Table 1 resumes the optimized parameters for each element.

3.2. Method Comparison: UAE vs. MWAD. In the analytical process, the sample preparation stage is decisive to obtain reliable results. Organic sample preparation is a challenge, and in the case of sorghum grains, the starch, protein, and fiber content may undergo extensive mineralization, before introduction to plasma-based techniques. In the last decades, UAE for trace analysis has dramatically expanded, reaching satisfactory outcomes leading to fast, efficient, and clean analytical sample preparation methods, achieving the aim of sustainable green chemistry [30-32].

Contrasting UAE with MWAD procedures, the last uses closed vessels decomposing organic matrices at elevated temperatures and/or pressure, evading analytical volatilization or sample loss. Meanwhile, UAE is an open system, resulting in the temperature and pressure necessary for complete digestion not being competently attained, seriously prejudiced by the sample particle size [30]. Thus, samples were milled until reaching a particle size distribution of fewer than $200 \mu \mathrm{m}$.

To assess whether the proposed sample preparation method (UAE) is equivalent to conventional MWAD, five sorghum samples were randomly selected. Digestions were performed in triplicate as indicated in Sections 2.4 and 2.5. The procedure was validated previously by Zaldarriaga Heredia et al. [26], and the performance is shown to be statistically equivalent to the standard AOAC method 985.35 [33].

Ultrasound extraction efficiency is increased as a result of increased medium temperature and increasing sonication time, forming a larger number of cavitation nuclei. Also, the acid type and its concentration affect the UAE. The oxidant combination between $\mathrm{HNO}_{3}$ and $\mathrm{H}_{2} \mathrm{O}_{2}$ has been widely used based on the reagents and matrix interaction. The strong oxidizing acid, $\mathrm{HNO}_{3}$, is used to enhance organic material mineralization, improving sample digestion via element soluble complex formation [30]. Also, when heating, $\mathrm{H}_{2} \mathrm{O}_{2}$ dissociates to hydroxyl radical $(\mathrm{OH})$ attacking proteins, carbohydrates, and fatty acids present in organic samples [34].

Nowadays, instead of searching for greening chemistry sample preparation procedures, one interesting alternative is the use of diluted reagents. The reduction in amounts of acid for organic samples' digestion leads to relevant advantages such as smaller residual acidity and residue amounts, cost reduction, and lower analytical blanks. In this sense, several recent applications demonstrated the potential of diluted nitric acid solutions [35-39].

Sorghum samples were digested using diluted acid by UAE, and results were compared with MWAD. Multielemental determination was carried out by MIP OES. Table 2 shows the $\mathrm{Cu}, \mathrm{K}, \mathrm{Mg}, \mathrm{Mn}, \mathrm{P}$, and $\mathrm{Zn}$ concentrations, with sorghum samples treated by UAE and MWAD. Both methods were statistically compared using a $t$-test $(\alpha=0.05$; $n=3$ ), and there were no significant differences between treatments. In order to compare the precision between MWAD and UAE, an F-test was performed, calculating each $F$-value for each element and sample, obtaining a range which was compared with $F_{\text {crit }}=39.00$. In all cases, the precision achieved by UAE was not significantly different from the MWAD method.

According to sustainable and green analytical procedures, UAE could be proposed as an attractive alternative to MWAD, being an interesting, quick, and nonexpensive option for sorghum grains sample preparation. As an added bonus, the UAE time consumption involved in sample pretreatment allows for a larger amount of sample to be run at one time; 50 samples can be digested in the water and ultrasonic bath in 90 minutes, unlike MWAD which has a rotor of 16 positions and can digest 16 samples in $30 \mathrm{~min}$. However, the time required for the MWAD, the cooling of the reactors before the opening, in addition to the washing that is approximately 30 minutes, increases the entire MWAD process time to approximately 90 minutes. The UAE advantage is not only in sample throughput but also the low cost and energy requirements of the US equipment compared to the MW digestor and the simpler availability of the polypropylene metal-free flasks tubes compared to the PTFE tubes. Thus, UAE has the benefit of simplicity of the procedure and speed of determination, improving productivity, with the possibility of being implemented in routine analysis in an analytical laboratory, being in compliance with green and equitable analytical chemistry.

To further highlight these advantages, the greenness of both sample preparation methods was compared by the hexagon tool [40]. This evaluation tool was carried out to assess analytical features of figures of merit, associated chemical and health risks, environmental friendliness, sustainability, and economic cost. The results are depicted in Figures 1(a) and 1(b). As shown in Figure 1, UAE and MWAD offer similar analytical performance; however, the 


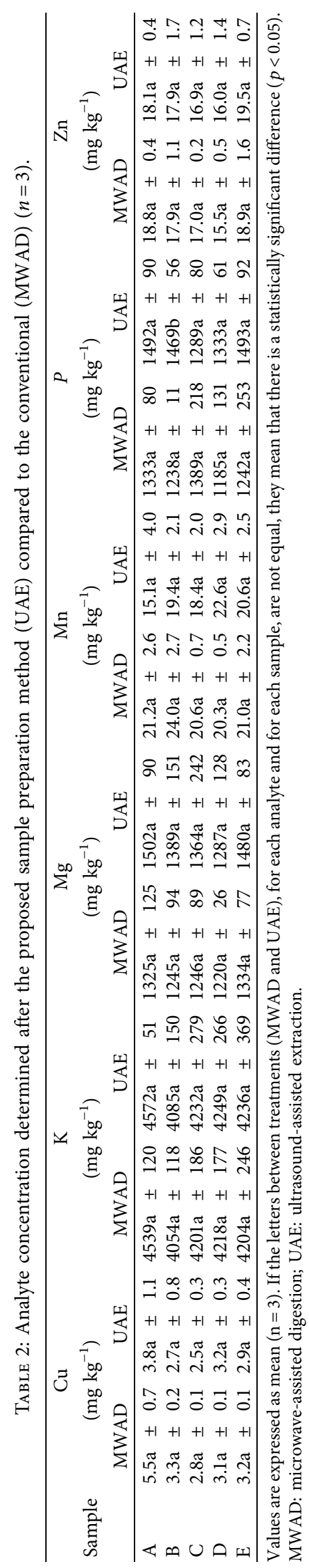




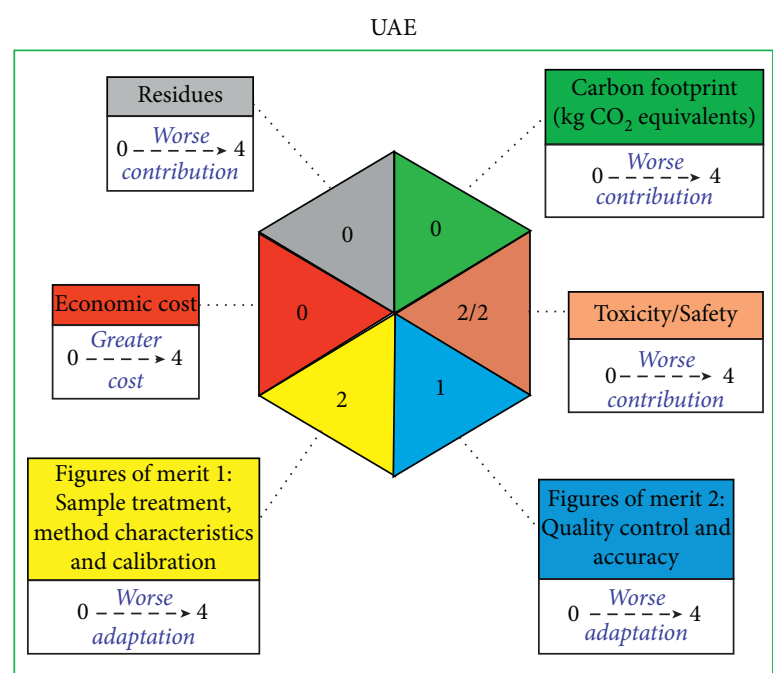

(a)

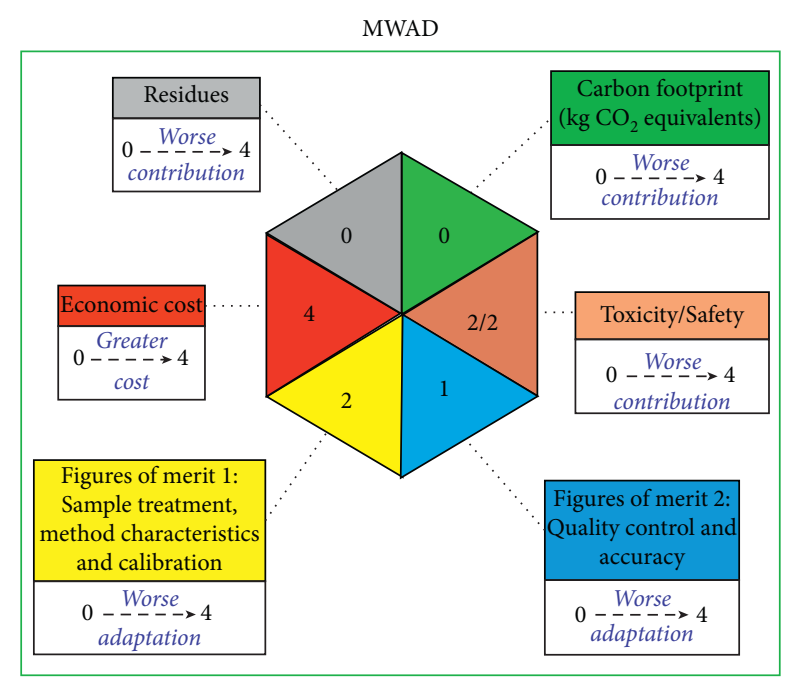

(b)

FIgure 1: Comparison of Green Analytical Procedure Index for (a) UAE and (b) MWAD sample preparation.

economic cost is higher for MWAD; thus, UAE could be a greener interesting alternative.

3.3. Analytical Performance. Afterward verifying the analytical results normality, the Levene test was accomplished to assess the homogeneity of the variance, indicative of the data homoscedasticity. For the linearity evaluation, the goodness of fit was established contrasting the fit lack variance with the pure error variance. Each model suitability was appraised by application of an F-test. Better than $0.99 R^{2}$ coefficients were attained for each analyte calibration curve.

The LOD and LOQ of each analyte were calculated, according to the up-to-date International Union of Pure and Applied Chemistry (IUPAC) recommendations, as 3.3 and 10 times the standard deviation (SD) of the measurement blanks $(n=10)$, respectively. Table 1 displays the figures of merit for $\mathrm{Cu}, \mathrm{K}, \mathrm{Mg}, \mathrm{Mn}, \mathrm{P}$, and $\mathrm{Zn}$ determination by MIP OES after treating samples by UAE. The recommended procedure reaches LOD between $0.6 \mathrm{mg} \mathrm{kg}^{-1}$ and $52 \mathrm{mg} \mathrm{kg}^{-1}$ and LOQ between $1.9 \mathrm{mg} \mathrm{kg}^{-1}$ and $172 \mathrm{mg} \mathrm{kg}^{-1}$ for $\mathrm{Cu}$ and $\mathrm{P}$, respectively.

For method validation, precision expressed as RSD\% obtained using the calibration curves was between $0.27 \%$ for $\mathrm{Mg}$ to $7.72 \%$ for $\mathrm{P}$, reaching good precision and attaining the conventional acceptance criterion ( Table 1). A CRM with a similar sample matrix was assessed in order to evaluate the trueness of the proposed UAE procedure under conditions selected in Section 2.4. Data comparison obtained after the application of the developed method with reference values is presented in Table 3. Recoveries between $82 \%$ and $110 \%$ were observed for all studied analytes. No significant differences were observed for $\mathrm{Cu}, \mathrm{K}, \mathrm{Mg}, \mathrm{Mn}, \mathrm{P}$, and $\mathrm{Zn}$. Analytical UAE method precision for the CRM was determined by the repeatability of the measurement set and was less than $6.33 \%$.
TABle 3: Analyte concentration certified in reference material and determined concentrations in certified reference material $(n=3)$.

\begin{tabular}{lccccccc}
\hline Analyte & \multicolumn{3}{c}{$\begin{array}{c}\text { Certified values } \\
\left(\mathrm{mg} \mathrm{kg}^{-1}\right)\end{array}$} & \multicolumn{4}{c}{$\begin{array}{c}\text { Determined } \\
\text { values }\end{array}$} \\
& $\left(\mathrm{mg} \mathrm{kg}^{-1}\right)$ & Recovery \% \\
\hline $\mathrm{Cu}$ & 0.66 & \pm & 0.08 & 0.67 & \pm & 0.04 & 101 \\
$\mathrm{~K}$ & 1290 & \pm & 70 & 1249 & \pm & 3 & 97 \\
$\mathrm{Mg}$ & 180 & \pm & 20 & 160 & \pm & 6 & 89 \\
$\mathrm{Mn}$ & 1.55 & \pm & 0.08 & 1.52 & \pm & 0.29 & 98 \\
$\mathrm{P}$ & 610 & \pm & 30 & 668 & \pm & 102 & 110 \\
$\mathrm{Zn}$ & 2.90 & \pm & 0.30 & 2.37 & \pm & 0.17 & 82 \\
\hline
\end{tabular}

Reference certified material: Maize Flour (NCS ZC 73010 Mealie).

The analytical performance of the developed UAE method is suitable for the determination of $\mathrm{Cu}, \mathrm{K}, \mathrm{Mg}, \mathrm{Mn}$, $\mathrm{P}$, and $\mathrm{Zn}$ in sorghum flour samples by MIP OES.

3.4. Analytical Application. The selected analytical conditions were applied for $\mathrm{Cu}, \mathrm{K}, \mathrm{Mg}, \mathrm{Mn}, \mathrm{P}$, and $\mathrm{Zn}$ determination in twenty sorghum types, mainly graniferous sorghum, dual-purpose sorghum, and forage sorghum. Table 4 exposes the concentrations of the 6 analytes found in the 20 sorghum hybrids examined. The concentration of the analyzed element ( $\mathrm{Cu}, \mathrm{K}, \mathrm{Mg}, \mathrm{Mn}, \mathrm{P}$, and $\mathrm{Zn}$ ) was similar to previous studies [41-45]. The content of macroelements was in the following order $\mathrm{K}>\mathrm{P}>\mathrm{Mg}$, while for microelements, $\mathrm{Mn}$ and $\mathrm{Zn}$ were similar but higher than $\mathrm{Cu}$.

Sorghum is a valuable grain, particularly due to its beneficial health components and its status as a practicable option for people with celiac disease and gluten intolerance. Hybrids with elevated levels of mineral elements such as Mn, $\mathrm{Mg}$, and $\mathrm{Zn}$ could be an effective component of functional foods and improve food nutritional quality.

This study reveals that $\mathrm{K}$ and $\mathrm{P}$ were recorded as dominant minerals in sorghum followed by $\mathrm{Mg}$. The $\mathrm{K}$ content was the most variable among hybrids (3641 $\mathrm{mg} \mathrm{kg}^{-1}-4806 \mathrm{mg} \mathrm{kg}^{-1}$ ). The $\mathrm{P}$ concentrations ranged 
TABLE 4: Mean analyte concentrations $(n=3)$ and standard deviations found in sorghum flours.

\begin{tabular}{|c|c|c|c|c|c|c|c|c|c|}
\hline \multirow[b]{2}{*}{ Sample } & \multicolumn{7}{|c|}{ Analyte } & \multirow[b]{2}{*}{$\begin{array}{c}\text { Sorghum commercial } \\
\text { types }\end{array}$} & \multirow[b]{2}{*}{ Hybrid } \\
\hline & $\begin{array}{c}\mathrm{Cu} \\
\left(\mathrm{mg} \mathrm{kg}^{-1}\right)\end{array}$ & $\mathrm{K}\left(\mathrm{mg} \mathrm{kg}^{-1}\right)$ & $\begin{array}{r}\mathrm{N} \\
(\mathrm{mg}\end{array}$ & $\begin{array}{l}\left.\mathrm{Mg}^{-1} \mathrm{~kg}^{-1}\right)\end{array}$ & $\begin{array}{c}\mathrm{Mn} \\
\left(\mathrm{mg} \mathrm{kg}^{-1}\right)\end{array}$ & $\mathrm{P}\left(\mathrm{mg} \mathrm{kg}^{-1}\right)$ & $\begin{array}{c}\mathrm{Zn} \\
\left(\mathrm{mg} \mathrm{kg}^{-1}\right)\end{array}$ & & \\
\hline I & $2.8 \pm 0.3$ & $3641 \pm 59$ & 1255 & \pm 35 & $21.6 \pm 0.1$ & $1394 \pm 25$ & $16.7 \pm 3.4$ & orghum & TOB $41 \mathrm{~T}$ \\
\hline II & $3.7 \pm 0.6$ & $4060 \pm 295$ & 1328 & 49 & $20.8 \pm 0.6$ & $1315 \pm 50$ & $19.5 \pm 3.5$ & orghum & TOB EXP 903 \\
\hline III & $3.8 \pm 1.1$ & $4572 \pm 51$ & 1502 & 90 & $15.1 \pm 4.0$ & $1492 \pm 90$ & $18.1 \pm 0.4$ & rghum & \\
\hline IV & $2.6 \pm 0.1$ & $4375 \pm 338$ & 1218 & 63 & $17.7 \pm 0.4$ & $1482 \pm 65$ & $14.5 \pm 3.3$ & hum & ACA XP \\
\hline $\mathrm{V}$ & $2.9 \pm 0.2$ & $4329 \pm 431$ & 1319 & 68 & $25.9 \pm 0.3$ & $1276 \pm 51$ & $16.8 \pm 2.9$ & rous sorghum & ACA GR 233 \\
\hline VI & $2.7 \pm 0.8$ & $4085 \pm 150$ & 1389 & \pm 151 & $19.4 \pm 2.1$ & $1469 \pm 56$ & $17.9 \pm 1.7$ & Graniferous sorghum & ARGEN \\
\hline VII & $3.2 \pm 0.4$ & $4528 \pm 44$ & 1329 & \pm & 19.7 & $1459 \pm 50$ & $19.8 \pm 1.6$ & Dual-purpose sorghum & $\begin{array}{c}\text { ARGENSOR } 151 \\
\text { DP }\end{array}$ \\
\hline VIII & $3.4 \pm 0.8$ & $4256 \pm 181$ & 1406 & 89 & $22.6 \pm$ & $1217 \pm 43$ & $22.1 \pm 0.9$ & Granifero & GEN $11 \mathrm{~T}$ \\
\hline IX & $3.1 \pm 0.3$ & $3917 \pm 929$ & 1356 & 84 & $21.6 \pm 0.9$ & $1397 \pm 29$ & $18.4 \pm 0.2$ & & \\
\hline $\mathrm{X}$ & $2.5 \pm 0.3$ & $4232 \pm 279$ & 1364 & \pm 242 & $18.4 \pm 2.0$ & $1289 \pm 80$ & $16.9 \pm 1.2$ & Dual-pu & GEN 4 \\
\hline XI & $3.2 \pm 0.3$ & $4249 \pm 266$ & 1287 & \pm 128 & $22.6 \pm 2.9$ & $1333 \pm 61$ & $16.0 \pm 1.4$ & & SUI \\
\hline XII & $2.9 \pm 0.4$ & $4236 \pm 369$ & 1480 & 83 & $20.6 \pm 2.5$ & $1493 \pm 92$ & $19.5 \pm 0.7$ & & SPRI \\
\hline XIII & $3.3 \pm 0.2$ & $4269 \pm 40$ & 1525 & 93 & $23.6 \pm 0.0$ & $1336 \pm 10$ & $21.8 \pm 0.1$ & & \\
\hline XIV & $3.2 \pm 0.2$ & $3822 \pm 58$ & 1285 & 36 & $24.8 \pm 1.7$ & $1457 \pm 21$ & $18.6 \pm 2.5$ & hum & TAMAR 2 GR \\
\hline XV & $2.9 \pm 0.4$ & $4401 \pm 456$ & 1370 & 40 & $21.5 \pm 2.0$ & $1473 \pm 60$ & $18.3 \pm 0.3$ & ferous sorghum & HS 26 LT \\
\hline XVI & $2.9 \pm 0.2$ & $4806 \pm 975$ & 1411 & 49 & $20.2 \pm 1.1$ & $1490 \pm 31$ & $15.4 \pm 6.8$ & hum & \\
\hline XVII & $3.0 \pm 0.4$ & $4379 \pm 138$ & 1367 & 34 & $21.2 \pm 1.8$ & $1506 \pm 14$ & $18.5 \pm 0.3$ & & \\
\hline XVIII & $2.8 \pm 0.2$ & $4382 \pm 511$ & 1410 & 82 & $20.0 \pm 0.2$ & $1449 \pm 10$ & $17.7 \pm 0.8$ & & \\
\hline XIX & $3.1 \pm 0.1$ & $4380 \pm 379$ & 1248 & 23 & $23.8 \pm 1.7$ & $1545 \pm 50$ & $18.3 \pm 0.5$ & Forage sorghum & GSD 3 \\
\hline $\mathrm{XX}$ & $2.9 \pm 0.6$ & $4749 \pm 194$ & 1465 & 76 & $19.3 \pm 4.1$ & $1482 \pm 20$ & $18.1 \pm 3.9$ & Forage sorghum & GSD 4 \\
\hline
\end{tabular}

from $1217 \mathrm{mg} \mathrm{kg}^{-1}$ to $1545 \mathrm{mg} \mathrm{kg}^{-1}$, and some results were settled below other reports $[41,42]$. In both cases, this could be related to the differences between hybrids and the soil type [45]. The $\mathrm{Mg}$ content in all hybrids was similar (1218 $\left.\mathrm{mg} \mathrm{kg}^{-1}-1525 \mathrm{mg} \mathrm{kg}^{-1}\right)$ to wheat flour $\left(970 \mathrm{mg} \mathrm{kg}^{-1}\right.$ ) and higher than cornflour $\left(470 \mathrm{mg} \mathrm{kg}^{-1}\right)$ as reported by Danish Food Composition Databank [46]. Since sorghum has a high $\mathrm{Mg}$ content, it could be considered a good source of this element.

Regarding microelements concentrations, $\mathrm{Mn}, \mathrm{Zn}$, and $\mathrm{Cu}$ contents ranged from $15.1 \mathrm{mg} \mathrm{kg}^{-1}$ to $25.9 \mathrm{mg} \mathrm{kg}$, $14.5 \mathrm{mg} \mathrm{kg}^{-1}$ to $22.1 \mathrm{mg} \mathrm{kg}^{-1}$, and $2.57 \mathrm{mg} \mathrm{kg}^{-1}$ to $3.7 \mathrm{mg} \mathrm{kg}^{-1}$, respectively. Zinc is known as being a good reducing agent as it can form a complex with sulfates, carbonates, sulfates, phosphates, phytates, and oxalates. Furthermore, $\mathrm{Zn}$ is an indispensable cofactor of more than 70 enzymes [47] and is an essential microelement in human nutrition. Its deficiency can trigger growth retardation, dermatitis, recurrent infections, diarrhea, and mental disturbances [48]. A highlight finding in this study is that the $\mathrm{Zn}$ content in all hybrids was similar to those reported in whole wheat flour $\left(\sim 22 \mathrm{mg} \mathrm{kg}^{-1}\right)$ and higher than in cornflour $\left(5 \mathrm{mg} \mathrm{kg}^{-1}\right)$ [46].

3.5. Correlation among Mineral Content. Figure 2 contains a colored representation of the matrix formed by the Pearson correlation coefficients calculated from the mineral concentration of studied sorghum samples. This initial correlation analysis showed the magnitude of the six metal concentrations and their correlation with one another. In general, all variables exhibited low positive or negative correlations with other variables. Highlighting, variable $\mathrm{P}$ is slightly negatively correlated with $\mathrm{Mg}(r=-0.62)$. Other variables negatively correlated were $\mathrm{P}$ and $\mathrm{K}(r=-0.30)$.

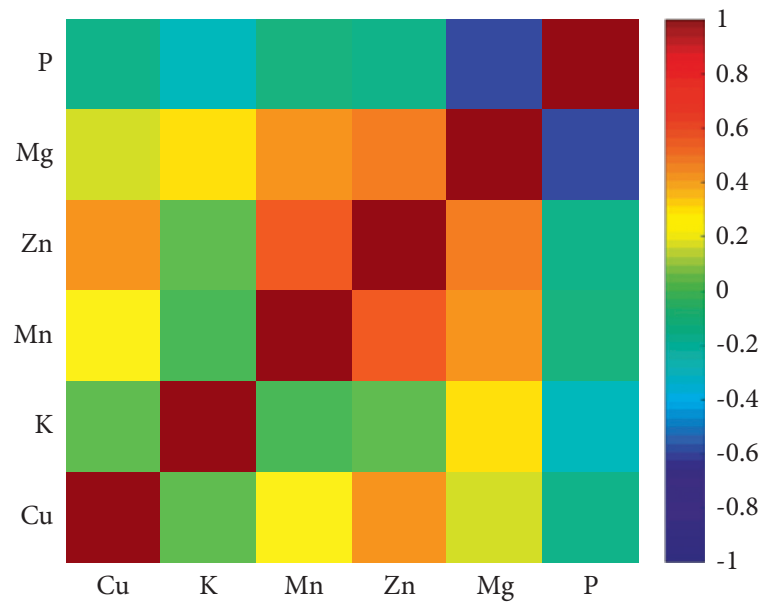

FIgURE 2: Correlation matrix among variables for the different sorghum genotypes evaluated.

Significant positive correlations were observed between $\mathrm{Mn}$ and $\mathrm{Zn}(r=0.58), \mathrm{Mn}$ and $\mathrm{Zn}(r=0.50), \mathrm{Mg}$ and $\mathrm{Mn}$ $(r=0.42)$, and $\mathrm{Cu}$ and $\mathrm{Zn}(r=0.42)$.

However, these correlation coefficients cannot reveal the fact that each group of sorghum hybrids may have a specific behavior. In order to provide a more comprehensive interpretation and to formulate general conclusions, multivariate data analysis was conducted.

3.6. Exploratory Analysis by PCA. The elemental composition is valuable to perform multivariate analysis because it can contain information about varieties, geographical origin, or other relevant information from sorghum. In this sense, 


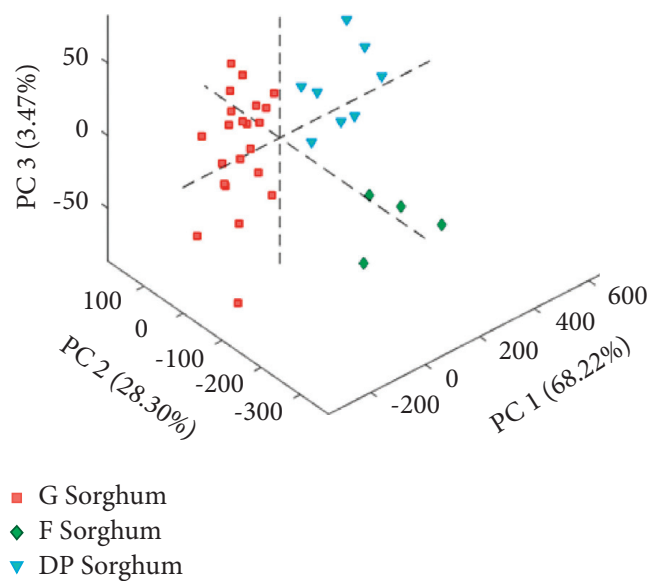

(a)

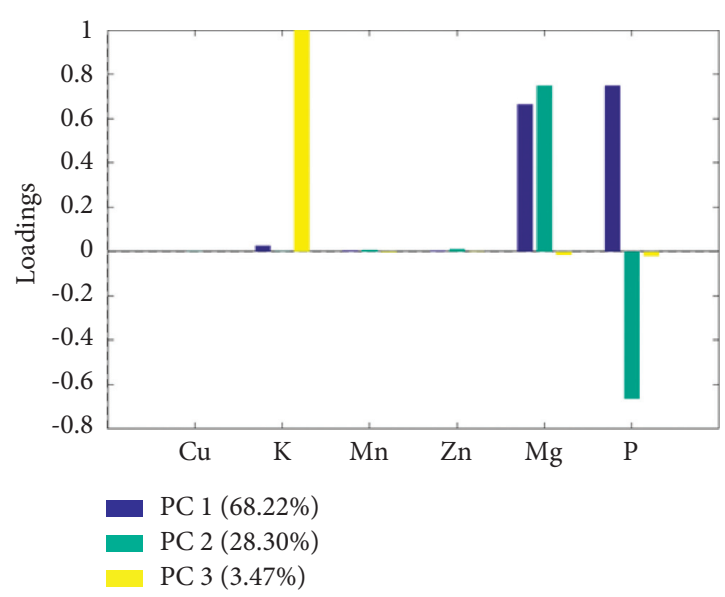

(b)

Figure 3: (a) Score scatter plots of the first 3 PCs obtained from PCA applied to a dataset corresponding to each mineral content on sorghum samples. The samples are shown according to the hybrids: G sorghum samples (red square), F sorghum samples (green diamond), and DP sorghum samples (light-blue triangle). Explained variance values of PC1, PC2, and PC3 are displayed in the corresponding axis. (b) Loading bar plots of the first 3 PCs obtained from PCA for each variable.

PCA is a meaningful multivariate tool to observe the behavior of data according to some particularities of samples. Previously, different preprocessing methods were evaluated, and the best one in terms of the explained variance obtained in the models was autoscaling. After finding that some studied variables showed variability on the acquired data, an independent PCA was conducted to assess differences among studied sorghum varieties. As a result of each analysis, the first three PCs were selected to represent data variability. Figure 3(a) represents the score plots of each dataset defined by the first three principal components calculated by PCA. The percentage of explained variance for individual components is shown on each axis summarizing a total of $99.99 \%$. It can be observed a clear differentiation of three classes related to the three varieties: graniferous sorghum (G), dual-purpose sorghum (DP), and forage sorghum (F). As can be seen in Figure 3(b), this discrimination is related to positive values of $\mathrm{PC} 1$ loadings for $\mathrm{Mg}$ and $\mathrm{P}$, which permitted to mainly differentiate the $G$ and DP sorghum groups, as well as positive and negative values related to PC2 loadings for $\mathrm{Mg}$ and $\mathrm{P}$, respectively, that contribute to discriminate F sorghum of the rest of samples. This result is closely matching with that obtained from the correlation analysis. Finally, PC3 loadings presented high positive values of $\mathrm{K}$ that also contributed to integral differentiation among samples.

From the point of view of varieties, this analysis allowed to evidence differences among them in terms of elemental composition and to achieve conclusions about those varieties more relevant from the point of view of human nutrition.

\section{Conclusion}

Regarding green and sustainable analytical procedures, using an ordinary ultrasound bath system for UAE makes sample preparation fast, simple, accurate, and less expensive than MWAD. Sorghum flour samples were suitably mineralized by UAE, enabling their introduction to the MIP OES, not evidencing significant differences with MWAD.

Aiming to explore the nutritional potential of sorghum, MIP OES was used for multielemental determination of sorghum flours in order to assess its mineral profile. Beholding it from food safety control and quality assurance, the proposed method is a magnificent substitute that could be straightforwardly applied in routine analysis laboratories, mainly due to the multielemental capabilities of MIP OES, with the benefit that the UAE is unassuming and respectable with GEAC, thus accelerating analysis times and improving performance and productivity.

The principal component analysis showed different groupings related to the variation in the elemental concentration of the various hybrids. The differentiation between varieties makes it possible to select those with the best nutritional profile for food product formulation.

\section{Data Availability}

Data used to support the findings of this study are available on request to the corresponding author (marianelasavio@ gmail.com).

\section{Conflicts of Interest}

The authors declare that they have no conflicts of interest.

\section{Acknowledgments}

The authors thank Consejo Nacional de Investigaciones Científicas y Tećnicas (CONICET) and the Agencia Nacional de Promoción Científica y Tecnológica (ANPCYT) for supporting this research. Also, research project was powered by the Universidad Nacional de La Pampa (Project nos. 99/ 2016 and 115/2020) and by Universidad Nacional de La 
Pampa (Project nos. 96, 2015 and 112/2020). The authors are grateful to the Instituto Nacional de Tecnología Agropecuaria (INTA) who kindly provided the sorghum samples.

\section{References}

[1] FAO, World Food and Agriculture - Statistical Pocketbook 2018, FAO, Rome, Italy, 2018.

[2] A. Pérez, "Caracterización y potencialidades del grano de sorgo (Sorghum bicolor L. Moench)," Pastos Y Forrajes, vol. 33 , no. 1 , pp. $1-25,2010$.

[3] J. Taylor and J. Kruger, Sorghum and Millets, AACCI, Maharashtra, India, 2018.

[4] É. A. A. Moraes, R. d. S. Marineli, S. A. Lenquiste et al., "Sorghum flour fractions: correlations among polysaccharides, phenolic compounds, antioxidant activity and glycemic index," Food Chemistry, vol. 180, pp. 116-123, 2015.

[5] P. M. Palavecino, M. C. Penci, G. Calderón-Domínguez, and P. D. Ribotta, "Chemical composition and physical properties of sorghum flour prepared from different sorghum hybrids grown in Argentina," Starch - Stärke, vol. 68, no. 11-12, pp. 1055-1064, 2016.

[6] S. S. L. Chan, E. L. Ferguson, K. Bailey, U. Fahmida, T. B. Harper, and R. S. Gibson, "The concentrations of iron, calcium, zinc and phytate in cereals and legumes habitually consumed by infants living in East Lombok, Indonesia," Journal of Food Composition and Analysis, vol. 20, no. 7, pp. 609-617, 2007.

[7] J. M. Awika and L. W. Rooney, "Sorghum phytochemicals and their potential impact on human health," Phytochemistry, vol. 65, no. 9, pp. 1199-1221, 2004.

[8] A. L. Girard and J. M. Awika, "Sorghum polyphenols and other bioactive components as functional and health promoting food ingredients," Journal of Cereal Science, vol. 84, pp. 112-124, 2018.

[9] K. G. Duodu, "Chapter 7 assaying sorghum nutritional quality," Methods in Molecular Biology, vol. 1931, 2019.

[10] N. Velázquez, H. Sánchez, C. Osella, and L. G. Santiago, "Using white sorghum flour for gluten-free breadmaking," International Journal of Food Sciences and Nutrition, vol. 63, no. 4, pp. 491-497, 2012.

[11] L. D. L. D. O. Pineli, R. P. Zandonadi, R. B. A. Botelho, V. R. De Oliveira, and L. F. De Alencar, "The use of sorghum to produce gluten-free breads (GFB): a systematic review," Journal of Advanced Nutrition and Human Metabolism, vol. 21, pp. 1-9, 2015.

[12] O. Q. Adiamo, O. S. Fawale, and B. Olawoye, "Recent trends in the formulation of gluten-free sorghum products," Journal of Culinary Science \& Technology, vol. 16, no. 4, pp. 311-325, 2018.

[13] N. Mtelisi Dube, F. Xu, and R. Zhao, "The efficacy of sorghum flour addition on dough rheological properties and bread quality: a short review," Grain \& Oil Science and Technology, vol. 3, no. 4, pp. 164-171, 2020.

[14] M. I. Curti, M. Belorio, P. M. Palavecino, J. M. Camiña, P. D. Ribotta, and M. Gómez, "Effect of sorghum flour properties on gluten-free sponge cake," Journal of Food Science \& Technology, vol. 54, 2021.

[15] R. Marcinkowska, J. Namieśnik, and M. Tobiszewski, "Green and equitable analytical chemistry," Current Opinion in Green and Sustainable Chemistry, vol. 19, pp. 19-23, 2019.

[16] W. Li, P. Simmons, D. Shrader, T. J. Herrman, and S. Y. Dai, "Microwave plasma-atomic emission spectroscopy as a tool for the determination of copper, iron, manganese and zinc in animal feed and fertilizer," Talanta, vol. 112, pp. 43-48, 2013.

[17] Ş. Sungur and F. Gülmez, "Determination of metal contents of various fibers used in textile industry by MP-AES," Journal of Spectroscopy, vol. 2015, 2015.

[18] N. Ozbek and S. Akman, "Microwave plasma atomic emission spectrometric determination of $\mathrm{Ca}, \mathrm{K}$ and $\mathrm{Mg}$ in various cheese varieties," Food Chemistry, vol. 192, pp. 295-298, 2016.

[19] A. Methods, "What causes most errors in chemical analysis?" Analytical Methods, vol. 5, no. 12, pp. 2914-2915, 2013.

[20] M. K. Jamali, T. G Kazi, M. B Arain et al., "A multivariate study: variation in uptake of trace and toxic elements by various varieties of Sorghum bicolor L," Journal of Hazardous Materials, vol. 158, no. 2-3, pp. 644-651, 2008.

[21] A.-M. Afify, H. S. El-Beltagi, S. M. El-Salam, and A. A. Omran, "Bioavailability of iron, zinc, phytate and phytase activity during soaking and germination of white sorghum varieties," PLoS One, vol. 6, no. 10, Article ID e25512, 2011.

[22] C. Chiremba, L. W. Rooney, and T. Beta, "Microwave-assisted extraction of bound phenolic acids in bran and flour fractions from sorghum and maize cultivars varying in hardness," Journal of Agricultural and Food Chemistry, vol. 60, no. 18, pp. 4735-4742, 2012.

[23] S. Armenta, S. Garrigues, F. A. Esteve-Turrillas, and M. de la Guardia, "Green extraction techniques in green analytical chemistry," TRAC Trends in Analytical Chemistry, vol. 116, pp. 248-253, 2019.

[24] C. Bendicho, I. De La Calle, F. Pena, M. Costas, N. Cabaleiro, and I. Lavilla, "Ultrasound-assisted pretreatment of solid samples in the context of green analytical chemistry," TRAC Trends in Analytical Chemistry, vol. 31, pp. 50-60, 2012.

[25] M. Singla and N. Sit, "Application of ultrasound in combination with other technologies in food processing: a review," Ultrasonics Sonochemistry, vol. 73, Article ID 105506, 2021.

[26] J. Z. Heredia, M. Cina, M. Savio, R. A. Gil, and J. M. Camiña, "Ultrasound-assisted pretreatment for multielement determination in maize seed samples by microwave plasma atomic emission spectrometry (MPAES)," Microchemical Journal, vol. 129, pp. 78-82, 2016.

[27] R. Bro and A. K. Smilde, "Principal component analysis," Analytical Methods, vol. 6, no. 9, pp. 2812-2831, 2014.

[28] A. C. Olivieri, "Practical guidelines for reporting results in single- and multi-component analytical calibration: a tutorial," Analytica Chimica Acta, vol. 868, pp. 10-22, 2015.

[29] C. B. Williams, R. S. Amais, B. M. Fontoura, B. T. Jones, J. A. Nóbrega, and G. L. Donati, "Recent developments in microwave-induced plasma optical emission spectrometry and applications of a commercial Hammer-cavity instrument," TRAC Trends in Analytical Chemistry, vol. 116, pp. 151-157, 2019.

[30] F. Krug and F. Rocha, Métodos de preparo de amostras para análise elementar, Sociedade Brasileira de Química, São Paulo, Brazil, 2016.

[31] I. Machado, I. Dol, E. Rodríguez-Arce, M. V. Cesio, and M. Pistón, "Comparison of different sample treatments for the determination of $\mathrm{As}, \mathrm{Cd}, \mathrm{Cu}, \mathrm{Ni}, \mathrm{Pb}$ and $\mathrm{Zn}$ in globe artichoke (Cynara cardunculus L. subsp. Cardunculus)," Microchemical Journal, vol. 128, pp. 128-133, 2016.

[32] J. D. Ruiz-Díaz, M. Savio, M. F. Moyano, E. E. Verni, L. D. Martinez, and R. A. Gil, "Ultrasonic-assisted dissolution of vegetable oils with tetrabutylammonium hydroxide for multielemental analysis by inductively coupled plasma mass spectrometry," Atomic Spectroscopy, vol. 36, no. 2, pp. 55-62, 2015.

[33] AOAC, "Minerals in ready to feed milk based infant formula and pet foods (atomic absorption spectrophotometric 
method) infant formula and medical diets," in Official Methods of Analysis of AOAC International, AOAC, Gaithersburg, MD, USA, 16th edition, 1996.

[34] T. G. Kazi, M. K Jamali, M. B Arain et al., "Evaluation of an ultrasonic acid digestion procedure for total heavy metals determination in environmental and biological samples," Journal of Hazardous Materials, vol. 161, no. 2-3, pp. 1391-1398, 2009.

[35] G. C. L. Araújo, M. H. Gonzalez, A. G. Ferreira, A. R. A. Nogueira, and J. A. Nóbrega, "Effect of acid concentration on closed-vessel microwave-assisted digestion of plant materials," Spectrochimica Acta Part B Atomic Spectroscopy, vol. 57, no. 12, pp. 2121-2132, 2002.

[36] C. A. Bizzi, E. M. M. Flores, J. S. Barin, E. E. Garcia, and J. A. Nóbrega, "Understanding the process of microwaveassisted digestion combining diluted nitric acid and oxygen as auxiliary reagent," Microchemical Journal, vol. 99, no. 2, pp. 193-196, 2011.

[37] F. C. Bressy, G. B. Brito, I. S. Barbosa, L. S. G. Teixeira, and M. G. A. Korn, "Determination of trace element concentrations in tomato samples at different stages of maturation by ICP OES and ICP-MS following microwave-assisted digestion," Microchemical Journal, vol. 109, pp. 145-149, 2013.

[38] J. T. Castro, E. C Santos, W. P Santos et al., "A critical evaluation of digestion procedures for coffee samples using diluted nitric acid in closed vessels for inductively coupled plasma optical emission spectrometry," Talanta, vol. 78, no. 4-5, pp. 1378-1382, 2009.

[39] M. H. Gonzalez, G. B. Souza, R. V. Oliveira, L. A. Forato, J. A. Nóbrega, and A. R. A. Nogueira, "Microwave-assisted digestion procedures for biological samples with diluted nitric acid: identification of reaction products," Talanta, vol. 79, no. 2, pp. 396-401, 2009.

[40] J. Płotka-Wasylka, "A new tool for the evaluation of the analytical procedure: green Analytical Procedure Index," Talanta, vol. 181, pp. 204-209, 2018.

[41] H. S. D. Martino, "Chemical characterization and size distribution of sorghum genotypes for human consumption," Artigo Original Article Review Instituto Adolfo Lutz, vol. 71, no. 2, pp. 337-344, 2012.

[42] P. Pontieri, "Mineral contents in grains of seven food-grade sorghum hybrids grown in a Mediterranean environment," Australian Journal of Crop Science, vol. 8, no. 11, pp. 15501559, 2014.

[43] C. L. Paiva, V. A. V. Queiroz, M. L. F. Simeone, R. E. Schaffert, A. C. de Oliveira, and C. S. da Silva, "Mineral content of sorghum genotypes and the influence of water stress," Food Chemistry, vol. 214, pp. 400-405, 2017.

[44] T. S. Abdelhalim, N. M. Kamal, and A. B. Hassan, "Nutritional potential of wild sorghum: grain quality of Sudanese wild sorghum genotypes (Sorghum bicolor L. Moench)," Food Sciences and Nutrition, vol. 7, no. 4, pp. 1529-1539, 2019.

[45] M. M. Tasie and B. G. Gebreyes, "Characterization of nutritional, antinutritional, and mineral contents of thirty-five sorghum varieties grown in Ethiopia," International Journal of Food Science, vol. 2020, Article ID 8243617, 2020.

[46] National Food Institute, Food Data, Technical University of Denmark, Kongens Lyngby, Denmark, 2019.

[47] C. D. Berdanier and L. A. Berdanier, Advanced Nutrition: Macronutrients, Micronutrients, and Metabolism, CRC Press, Boca Raton, FL, USA, 2015.

[48] WHO/FAO, Guidelines on Food Fortification with Micronutrients, WHO, Geneva, Switzerland, 2006. 